\title{
Fatores estressores que influenciam na qualidade de vida, gerando danos à saúde do policial militar
}

\author{
Stressors that influence in the quality of life generating damage to the health of the military police
}

Régis Coelho Bernardino ${ }^{\dagger *}$, Adriana Vasconcelos da Silva Bernardino

Como citar esse artigo. Bernardino, RC; Bernardino, AVS. Fatores estressores que influenciam na qualidade de vida, gerando danos à saúde do policial militar. Revista Mosaico. 2018 Jul./Dez.; 09 (2): 02-09.

\section{Introdução}

A contemporaneidade encerra mudanças profundas na maneira do homem se relacionar, na esfera afetiva, na constituição de sua família, nos papéis e nas funções sociais desempenhadas. O mundo em que vivemos, por alguns autores definido como pósmoderno e, para outros, ainda pertencente à modernidade (Guiddens, 2002), reveste-se de algumas características que interferem diretamente na forma das pessoas se relacionarem e na maneira como as reações vivenciais podem impactar em suas vidas.

As reações vivenciais (respostas emocionais às nossas vivências) produzem sentimentos no ser humano, que, por sua vez, podem produzir como respostas o estresse, o esgotamento, a ansiedade e outros transtornos, frente àquela situação que nos sensibiliza (Ballone, Neto \& Ortolani, 2002).

Ainda nesse contexto do pós-moderno, identificamos o aumento significativo das doenças psicossomáticas (termo bastante utilizado quando uma doença, física ou não, tem seu princípio na mente, no aspecto emocional), da medicação excessiva, da busca rápida pelo alívio do sofrimento psíquico, da violência, do empobrecimento econômico da população e da precariedade na comunicação e no estabelecimento de laços afetivos. Estes fatores vêm contribuindo para um comprometimento dos valores, da ética e de referenciais seguros, deixando o homem com uma enorme sensação de desamparo e sofrimento emocional.

Dessa maneira, tomaremos como base o trabalho do policial militar, considerado por diversos autores

\footnotetext{
Afiliação dos autores:

${ }^{\dagger}$ Especialista em Gestão Estratégica de Negócios em Tempo de Mudanças - MBA Executivo, Pró-Reitoria de Pesquisa e Pós-Graduação da Universidade de Vassouras, Vassouras/RJ.

* Coordenadora e Docente do Curso de Graduação em Psicologia da Universidade de Vassouras, Vassouras/RJ
}

Email para correspondência: regis_coelho@oi.com.br 
(Holloway, 1997; Bretas, 1998; Minayo, Souza \& Constantino, 2008; Minayo, Assis \& Oliveira 2011) como um dos mais estressantes de todos os ofícios e, possivelmente, por esta razão, apresenta com frequência quadros de estresse e ansiedades por estar constantemente exposto ao perigo e à violência, tendo ainda como função, intervir em situações de conflito e tensão. Assim, o objetivo do presente estudo é provocar uma reflexão sobre as condições atuais de trabalho do policial militar, a fim de identificar os problemas existentes e, consequentemente, estimular que novas pesquisas possam surgir e contribuir para que sejam levantadas alternativas que minimizem ou previnam os impactos da ansiedade e do estresse presentes no cotidiano do policial militar, contribuindo para o aumento na qualidade de vida, de melhores condições de saúde e segurança. E, consequentemente, do aumento do padrão de serviços prestados à população.

\section{Referencial teórico}

\section{A História da Polícia Militar}

Do início da história colonial até 1603 , o país não apresentava nenhuma organização policial. Todos os três poderes: Executivo, Legislativo e Judiciário, estavam concentrados nas mãos dos governadores. A primeira Corporação da Polícia existente na Cidade do Rio de Janeiro foi a Guarda Escocesa, trazida por Villegaignon, em 1555. Os mesmos registros apontam que a primeira cadeia pública foi construída em 1567 , no morro do Castelo (Minayo, Souza \& Constantino, 2008).

O Conselho de Vereança, estabelecido pelo Governador da época (1567-1572), Mem de Sá, foi quem editou as primeiras posturas referentes à atividade policial, esboçando o estabelecimento de penas para aqueles que fizessem uso do "jogo" como forma de vício (Minayo, Souza \& Constantino, 2008; Minayo, Assis \& Oliveira 2011).

Uma nova estrutura de Polícia Militar surgiu em 1626. Tratava-se de uma organização que seguia os modelos dos quadrilheiros existentes em Lisboa. Sua organização se justificava pela necessidade de fiscalização do pagamento de impostos sobre as casas de pasto, fogos de artifício, tabernas que permaneciam abertas até depois da meia-noite, lançamento de barcos e canoas, restos de material de construção, taxas de carceragem, taxas sobre açoites em escravos, licença para construção de moradias e venda de capim (Minayo, Souza \& Constantino, 2008; Minayo, Assis \& Oliveira 2011).

Em 1760, diante do aumento alarmante da criminalidade na cidade do Rio de Janeiro e da decadência da organização dos quadrilheiros, O Marquês de Lavradio criou e regulamentou o Corpo dos Guardas Vigilantes (Minayo, Souza \& Constantino, 2008; Minayo, Assis \& Oliveira 2011).

Aos poucos foram sendo criadas outras corporações policiais que tinham por objetivo o de ser uma "resposta civilizada às insatisfações públicas relativas às arbitrariedades produzidas pelo uso da força e pelas intervenções descontínuas e truculentas dos exércitos e dos intendentes diante dos conflitos sociais" (Minayo, Souza \& Constantino, 2008 p. 43).

Posteriormente, mais precisamente em 1808, a Família Real Portuguesa que vivia, em Portugal, constantemente ameaçada pela iminente invasão de Napoleão Bonaparte, decidiu então se mudar para o Rio de Janeiro, trazendo consigo a sua Corte, com cerca de 15.000 pessoas. Inaugurava-se uma nova fase dentro da história da cidade do Rio de Janeiro, dando início a sucessivas modificações no organismo policial que vigorava até o momento (Bretas, 1998).

Adaptando aos modelos de instituições já experimentadas em Lisboa, o príncipe regente cria no Rio de Janeiro uma Intendência Geral de Polícia. Tal Organização representava um órgão administrativo que possuía poderes judiciais, sendo responsáveis por uma grande variedade de tarefas na administração da cidade. Como a Intendência não dispusesse de pessoal para fazer valer suas determinações, em 13 de maio de 1809, dia do aniversário do Príncipe Regente, D. João VI criou a Divisão Militar da Guarda Real da Polícia da Corte (DMGRP). Formada por duzentos e dezoito guardas, era composta por um Estado-Maior, três companhias de Infantaria e uma companhia de Cavalaria. A Divisão tinha sua estrutura semelhante à do exército e sua função era a de garantir a ordem pública (Bretas, 1998).

A primeira grande reforma desse arranjo Institucional aconteceu no ano de 1831, quando o regente Diogo Antônio Feijó extinguiu a Guarda Real, sendo a mesma substituída por uma Organização paramilitar e civil denominada Guarda Municipal. Composta por cidadãos não profissionalizados, que não recebiam por este serviço e recrutados entre cidadãos de posse, essa nova Organização estava com os dias contados. No seu lugar, foi implantado um novo Corpo de Guardas Municipais Permanentes, do qual derivaram as instituições policiais uniformizadas de formato militar que ainda hoje fazem o policiamento urbano no Rio de Janeiro (Minayo, Souza \& Constantino, 2008; Minayo, Assis \& Oliveira 2011).

[...] Nas instruções baixadas por Feijó, a influência da filosofia liberal era nítida. O Código Criminal oferecia um arcabouço jurídico que limitava o arbítrio dos policiais. Nele estava escrito que "as patrulhas da Polícia Militar cumpririam com seu dever sem exceção de pessoa alguma, sendo com todos prudentes, circunspetas, guardando aquela civilidade e aquele respeito devidos 
aos direitos dos cidadãos (Holloway, 1997. p.94).

A ideia do regente era terminar com a violência que vinha sendo praticada contra o povo desde a criação da Polícia. Feijó esperava que a nova Polícia Militar ocupasse o lugar de uma instituição capaz de prevenir e reprimir distúrbios e estabelecer a ordem social, por meio de métodos mais racionais e humanitários, como por exemplo, através da privação de liberdade e da aplicação de multas (Holloway, 1997).

Em 1866, este Corpo de Guardas Permanentes recebeu o nome de Polícia da Corte e, em 1920, recebeu a designação formal de Polícia Militar. No site corporativo consta que a instituição já passou por doze denominações diferentes que seguiram com a história do Brasil e do Estado do Rio de Janeiro (Minayo, Souza \& Constantino, 2008; Minayo, Assis \& Oliveira 2011).

No ano de 1942, um estado de guerra existia entre a Alemanha e o Brasil e o governo do Brasil organiza-se para encaminhar à Europa uma Divisão de Infantaria Expedicionária. Na ânsia de completar seus quadros, praças graduados da Polícia Militar do Distrito Federal (PMDF) são incorporados ao Exército. Alguns policiais militares foram remanejados para a FEB, dentre eles, o $3^{\circ}$ Sargento Max Wolff Filho, que faleceu durante um combate na Itália, na ocasião, como $2^{\circ}$ Sargento. (PMERJ, 2017)

Em 1960, com a transferência da capital do país para Brasília, a cidade do Rio de Janeiro, antigo Distrito Federal, passou a ser chamada de Estado da Guanabara. Dessa forma, a denominação Polícia Militar do Distrito Federal passou a ser conhecida por Polícia Militar do Estado da Guanabara (PMEG). Nas demais regiões do Estado, a corporação recebeu o nome de Polícia Militar do Estado do Rio de Janeiro com a sigla PMRJ. (PMERJ, 2017)

Durante o período da ditadura militar (19641985), a polícia foi designada para enfrentar os opositores políticos do regime. Neste período a polícia desempenhou funções estritamente militares. Deixou de ser vista como uma instituição encarregada da proteção e defesa do povo para atuar na segurança nacional e táticas anti-guerrilha e anti-protestos. Esta doutrina de segurança nacional foi usada para justificar inúmeros atos de crueldade que aconteceram durante essas duas décadas. Episódios de tortura e morte passaram a ser práticas constantes e a impunidade reinava entre os detentores do poder. (Minayo, Souza \& Constantino, 2008; Minayo, Assis \& Oliveira 2011).

Os esquadrões da morte, como a Scuderie Detetive Le Cocq, liderados pelos 'Homens de Ouro', eram compostos por policiais que realizavam segurança particular para empresários locais, principalmente nas favelas. Podemos dizer que tais grupos tenham servido de modelos para as milícias, encontradas nos últimos anos. (Bretas, 1998).
Em 1974, o Governo do Distrito Federal resolve unir os dois estados através da Lei Complementar $\mathrm{n}^{\circ} 20$, que expunha a junção do Rio de Janeiro e da Guanabara em 15 de março de 1975. Nesta mesma lei, a nova unidade da federação foi nomeada como Estado do Rio de Janeiro e, a partir de então, as duas Corporações policiais-militares foram unificadas. (PMERJ, 2017).

Na década de 1980, o coronel Carlos Magno Nazareth Cerqueira, oficial culto e professo defensor dos Direitos Humanos, é nomeado para assumir o comando da corporação. Ele ensaia a primeira ação em busca de mudança dos paradigmas operacionais da Polícia Militar, objetivando apresenta-la com um caráter mais democrático, em substituição da imagem repressora com que fora desenhada ao longo de dois governos de exceção: o "Estado Novo" e os "Anos de Chumbo". Coronel Cerqueira empenhou esforços para a implantação de doutrinas e projetos na PMERJ que até hoje são desenvolvidos, como o PROERD (Programa Educacional de Resistência às Drogas e à Violência) e a filosofia de Policiamento Comunitário (PMERJ, 2017).

Com o fim da ditadura, o que se esperava era que a violência, tão presente nesta época, diminuísse. No entanto, paradoxalmente, os seguintes 25 anos foram alguns dos mais violentos da história do Brasil. Conforme a Tabela 1 e o Gráfico 1 observamos que, entre os anos 1991 e 2016, ocorreram uma média de 7.248 homicídios por ano, apenas no estado do Rio de Janeiro, valores comparáveis com as áreas urbanas dos países em guerra civil. (ISP, 2017).

O conjunto de problemas que a maioria dos estudiosos observa em relação à corporação, foi explicitado de forma clara pelo filme de ficção Tropa de Elite, em 2007. A obra de ficção retrata que grande parte dessa onda de violência se deu por causa da dinâmica que se formou, estabelecendo um abismo entre o Estado e as favelas que surgiram a partir dos anos 1980, tornando o policiamento nestes territórios muito mais difícil. A mídia passou a relacionar habitantes da favela com a criminalidade, sem levar em conta que apenas uma parcela dessa população estivesse envolvida no crime. Os meios de comunicação e o governo promoveram e incentivaram esta imagem. O que alimenta uma constante sensação de medo que se manifesta sempre que a questão envolva alguma experiência em relação às favelas. (Minayo, Souza \& Constantino, 2008; Minayo, Assis \& Oliveira 2011)

A imagem do Policial Militar passou, desde então, a estar associada a um grupo que, para cumprir seu dever, vai às últimas consequências, ultrapassando os limites da legalidade, chegando até a cometer torturas. Estes "heróis" também são vistos como àqueles que combatem e ao mesmo tempo convivem com a criminalidade. São reconhecidos como suscetíveis a subornos e promiscuamente compactuando com a ilegalidade e com o poder. (Minayo, Souza \& Constantino, 2008; 
Minayo, Assis \& Oliveira 2011)

No cumprimento de sua Missão contemporânea, a Polícia Militar do Rio de Janeiro atua em sete grandes áreas, cada uma dessas áreas está vinculada a um Comando de Policiamento de Área (CPA).

Dentro de sua missão constitucional, a Polícia Militar é responsável por um grande número de tarefas dentre as quais destacamos algumas: atuar contra o crime e a violência, na repressão de assaltantes, sequestradores, grupos de extermínio e traficantes; realizar patrulhamento motorizado em todos os recantos do Estado, durante as madrugadas, à beira das estradas; realizar serviços de patrulhamento às portas das escolas públicas e privadas, faculdades e universidades, como também estar presente em comemorações cívicas; trabalhar no policiamento das orlas marítimas e nas praias das diversas regiões litorâneas do Estado, especialmente, nos períodos quentes; atuar no policiamento nos grandes centros comerciais em todas as cidades do estado, além de prestar serviços nos principais pontos turísticos; realizar a segurança dos grandes eventos esportivos, oficiais e públicos, em estádios, ginásios e congêneres; Estar presente nos serviços de policiamento de grandes eventos e festas populares, tais como: eleições, Carnaval, Natal, Réveillon etc.; atuar, durante 24 horas, no serviço de segurança externa de todos os presídios e complexos penitenciários, escoltas de presos de alta periculosidade; e controlar e orientar o trânsito urbano (PMERJ, 2017).

Além do desempenho rotineiro das tarefas mencionadas, muitas vezes, o policial militar tem suas horas de trabalho ampliadas pelas demandas nas ocorrências, e seus períodos de repouso ou de férias interrompidos pelas necessidades que se apresentam. Frequentemente, a folga do policial militar não significa descanso, pois o percentual dos que trabalham em outra atividade - quase sempre em empresas e em serviços de segurança - é muito mais elevado. E, ainda, se enquadram dentro de uma política salarial defasada e desvalorizada diante de outras profissões (Minayo, Souza \& Constantino, 2008).

Outro motivo é que boa parte dos policiais militares são conhecidos nos bairros ou favelas onde moram, mesmo quando tentam disfarçar seus uniformes ou insígnias corporativas. Muitos destes policiais acabam como vítimas de emboscadas por parte de bandidos a quem perseguem. As formas como essas condições se conjugam, contribuem para implicações danosas à saúde (mental) dos profissionais, cuja configuração favorece o aumento do sofrimento psíquico, podendo se desdobrar em quadros psicossomáticos das mais diversas ordens. (Minayo, Souza \& Constantino, 2008; Minayo, Assis \& Oliveira 2011).

A polícia militar, pela natureza de sua missão, submete o policial a constantes desgastes físico e mental. Sua prática profissional, normalmente, se dá em ambientes hostis, tensos, de violência e, às vezes, desumanos. Convivem com a injustiça social e, sobretudo, com o risco frequente de matar ou morrer. (Silva \& Vieira, 2008).

Pelas razões até aqui apresentadas, podemos compreender o motivo pelo qual o estresse seja um fator constantemente presente na vida do policial militar e pode influenciar de maneira decisiva no seu comportamento dentro e fora de sua atividade profissional. (Delboni. 1997).

\section{Fatores estressores e a vitimização do policial militar}

"O risco iminente, a constante insegurança e violência vivenciados pelos policiais militares do Rio de Janeiro se concretizam na vitimização por traumas, lesões ou mortes, ocorridas no exercício da missão de prevenir crimes e contravenções e de manter a ordem" (Minayo, Souza \& Constantino, 2008,p.193). Os policiais que trabalham nas ruas estão, além de mais expostos à violência do confronto, também mais vulneráveis a problemas de saúde decorrentes de suas atividades, a exemplo, os quadros de estresse e esgotamento.

O estresse é uma ocorrência global, tanto do ponto de vista físico, quanto do ponto de vista emocional. As primeiras pesquisas médicas sobre o estresse estudaram uma vasta constelação de alterações orgânicas produzidas no organismo diante de situações de agressão. Do ponto de vista psicoemocional, o estresse surge quando a pessoa se encontra diante de uma situação entendida como geradora de insegurança ou de ameaça (Ballone, Neto \& Ortolani, 2002). Trata-se da resposta de um organismo submetido a uma situação pela qual ele terá de lutar e se adaptar, consequentemente, sobreviver.

A ansiedade é o reflexo emocional do estresse, e se trata de uma reação fisiológica, responsável pela adaptação do organismo às situações que exigem mudanças. A partir de um ponto excedente, ao invés de contribuir para a adaptação, a ansiedade produzirá a falência da capacidade adaptativa. Nesse ponto crítico, onde a ansiedade é tanta que já não favorece a adaptação, ocorre o esgotamento (Ballone, Neto \& Ortolani, 2002).

Estudos realizados por Souza e Minayo (2005) revelam que, fora do ambiente de trabalho, os policiais são vítimas de fortes sentimentos de rejeição da população à categoria e da maior proximidade com bandidos que aproveitam para "ir à forra". Nessas situações, o uniforme, a identidade funcional e os distintivos são dispositivos que facilitam a vitimização. Como estratégia para tentar driblar o sentimento de insegurança, a condição de ser um policial militar acaba por impor ao mesmo um "estilo de vida" diferenciado. $\mathrm{O}$ policial se sente constantemente vigiado e essa situação faz com que se sinta sob uma constante ameaça 
e necessidade de adaptação. Um dos grandes inimigos da saúde das pessoas já não é uma crise ocupacional, perturbação emocional ou situação perigosa, mas passa a ser também o estado prolongado e constante de preocupação, alerta e ansiedade, que caracteriza uma forte carga de estresse (Albrecht, 1990; Moraes \& Kilimnik, 1992).

Os policiais militares, especialmente, vivem em estado de permanente tensão e têm dificuldade para relaxar, para equilibrar tempos de trabalho e nãotrabalho. Tais fatores podem elevar os batimentos cardíacos, a tensão muscular, a pressão arterial e diminuir a atividade do sistema imunológico. Os efeitos em longo prazo são debilitantes e expõem os policiais a um grande número de riscos médicos e psicológicos à saúde. Alguns desses riscos podem ser prejudiciais à carreira desse profissional e altamente letais (Lipp, 1996, 1996).

Outro fator a ser considerado nesse contexto de trabalho do policial militar, é que as fontes de tensão e de estresse são mediadas pelas diferenças próprias a cada indivíduo, ou seja, em uma mesma situação de trabalho, elementos negativos e estressantes não atingem de forma homogênea todas as pessoas. Segundo Moraes et al. (1995, p. 13), "“...] as diferenças individuais também explicam, juntamente com a característica do agente estressor, os resultados de estresse".

O que queremos enfatizar com isso, é que assim como as pessoas reagem diferentemente diante de um mesmo estímulo capaz de produzir um determinado sintoma, também em relação aos fatos ou acontecimentos do destino, pessoas diferentes manifestam sentimentos diferentes. O sintoma ou sentimento depende sempre da sensibilidade de cada um, mais do que do próprio fato ou acontecimento em si. A reflexão de Brant e MinayoGomez contribui para entendermos melhor a situação aqui explicitada:

[...] É importante reconhecer que o sofrimento não tem uma manifestação única para todos os indivíduos de uma mesma família, cultura ou período histórico. O que é sofrimento para um, não é, necessariamente, para outro, mesmo quando submetidos às mesmas condições ambientais adversas. $\mathrm{Ou}$ ainda, aquilo que é sofrimento para alguém, pode ser prazer para outro e vice-versa. Um acontecimento, como algo capaz de provocar um espanto, em um determinado momento pode significar sofrimento; em outro, pode ser vivenciado como satisfação. Resta ainda lembrar que no sofrimento é possível encontrar uma mesclagem de prazer e dor, simultaneamente (Brant \& Minayo-Gomez, 2004, p.215).

As vivências, que são os fatos ou acontecimentos representados particularmente em cada um de nós, causam também sentimentos particularmente variados em cada um de nós: ansiedade, medo, alegria, angústia, raiva, apreensão etc. Assim sendo, podemos dizer que as reações vivenciais são as respostas emocionais às nossas vivências, tal como os sintomas que apresentamos como, por exemplo, o estresse, é uma resposta aos estímulos que nos sensibilizam (Ballone, Neto \& Ortolani, 2002).

A estafa também é um risco para o policial militar e, além dos problemas psicológicos, apresenta também sintomas físicos, tais como dores de cabeça, insônia, perda de peso e falta de fôlego, e comportamentais manifestados através de maior irritabilidade e expressões de raiva, diminuição da tolerância à frustração e variações de humor (Quick et al., 2003).

Codo, Sampaio e Hitomi (1993) salientam que saúde e doença não são fenômenos isolados, definidos em si mesmos. São fenômenos que estão profundamente vinculados ao contexto socioeconômico e cultural, tanto em relação às suas produções quanto em relação às soluções.

A motivação e a consciência de que podemos obter reconhecimento, gratificação e prazer no trabalho são componentes essenciais da realização profissional. Em contrapartida, a dor remete para o sofrimento no trabalho. Prazer e dor constituem um par dialético (Minayo, Souza \& Constantino, 2008).

Atualmente, sempre que se ouve o depoimento de um policial militar, aparecem muito mais e com contundência os momentos de desprazer associados notadamente à natureza do trabalho, à jornada excessiva, à falta de condições adequadas dos equipamentos e instrumentos, aos problemas de deficiência na assistência à saúde, à insuficiente retribuição financeira e ao sentimento de desvalorização profissional. Muitos oficiais mencionam também como negativa a rigidez hierárquica que embota a criatividade e impede a participação dos policiais em decisões que lhes dizem respeito. Por fim, frequentemente, ressaltam a distorção da imagem do policial que acreditam ser projetada para a sociedade e alimentada pela mídia. Além do fato de que ingerências políticas impedem a continuação de projetos e tornam descontínuas atividades iniciadas em gestões anteriores (Minayo, Souza \& Constantino, 2008).

Em decorrência disso tudo o que relatamos até aqui, o conhecido Transtorno de Estresse PósTraumático (TEPT) constitui-se em uma manifestação recorrente no meio dos Policiais Militares do Estado do Rio de Janeiro.

Caracterizado por uma intensa crise de ansiedade precipitada por um trauma, o traço essencial desse transtorno é que seu desenvolvimento está ligado a um evento traumático de dimensão extrema. Uma fração significativa dos sobreviventes de experiências traumáticas desenvolve uma constelação aguda de sintomas de TEPT, que pode ser dividida em três grupos: revivescência do trauma, esquiva ou entorpecimento emocional e hiperestimulação autonômica. O TEPT é diagnosticado se esses sintomas persistirem por quatro semanas após a ocorrência do trauma e se redundarem em comprometimento social e ocupacional, significativos. 
(Figueira \& Mendlowicz, 2003) Hoje, estudos baseados na prática clínica têm mostrado que, em lugar de um transtorno de estresse pós-traumático, de etiologia bem definida, muitos indivíduos - inclusive os que estão em situação de guerra - desenvolvem uma forma de 'alerta permanente' que, ao mesmo tempo, provoca fadiga e é proteção diante do perigo (Minayo, Souza \& Constantino, 2008).

Já o estresse ocupacional pode ser definido como um processo em que o indivíduo percebe demandas do trabalho como estressoras, as quais, ao excederem sua capacidade de adaptação e condição de enfrentamento, causam-lhe reações negativas (Minayo, Souza \& Constantino, 2008).

Os sintomas mais comuns relacionados aos quadros aqui apresentados podem ser manifestados através de alterações físicas ou psicológicas e são eles: dores musculares, cefaleias, enxaquecas, fadiga fácil, úlcera, palpitações, dores abdominais, abafamento no peito, taquicardia, enfarte precoce, dores generalizadas no corpo, adinamia, artrite, urticária, emagrecimento, asma e infecções graves. Como já afirmamos, outros sintomas também podem manifestar-se em nível psicológico, sendo os mais frequentes: mãos geladas, redução da capacidade de memorização, ressecamento na boca, incapacidade para trabalhar, pesadelos, desconfortos no estômago, inseguranças diversas, alterações no apetite, diarreia, perda da libido sexual, aumento súbito de motivação, entusiasmo repentino, tensão muscular, sentimento de fuga, apatia, depressão ou ira prolongada, insônia, sudorese, enjôos, má digestão, tiques nervosos, aumento da pressão arterial, fixação de pensamentos pessimistas ou em conteúdos específicos, desinteresse, irritabilidade, alterações cardíacas, ansiedade ou angústia, tonteiras, hipersensibilidade emotiva, alterações frequentes no humor e quadros de bruxismo (Lipp, 1996).

No contexto da formação da identidade, acrescentamos a baixa-autoestima relacionada às cobranças por causa da falta de qualidade do serviço prestado à população. Os agravos emocionais frequentemente geram sintomas de depressão, desejo de suicídio e, menos frequentemente, síndrome de pânico (Minayo, Souza \& Constantino, 2008).

Por fim, apontamos como última categoria dentre os fatores estressores, constantemente vivenciados pelos policiais Militares, aqueles que acometem diretamente a qualidade de vida destes. Destacamos como principais vulnerabilidades a questão salarial, a falta de reconhecimento, o foco excessivo nos aspectos profissionais, a vivência de perdas e a falta de qualidade na alimentação (Minayo, Souza \& Constantino, 2008).

\section{Materiais e métodos}

A metodologia empregada no trabalho foi a revisão de literatura em obras indicadas em orientação e naquelas encontradas em bases de dados como periódicos CAPES, Google acadêmico, banco de teses e dissertações, BVS, SciELO e PEPSIC, no período de 1991 a 2017, período tomado como referência pelos dados estatísticos oficiais, que apontam esse período como o de maior crescimento da violência no Estado do Rio de janeiro. As palavras-chave utilizadas foram "Policial Militar", "Qualidade de vida" e "Estresse". Foram critérios de exclusão: artigos publicados antes de 1991 e aqueles que se referiam ao estresse laboral de um modo geral ou que abordavam o tema qualidade de vida voltado para o envelhecimento. Somandose todas as bases de dados, foram encontrados 548 artigos. Através da leitura dos títulos e das referências bibliográficas que apresentavam, foram descartados aqueles que não preenchiam os critérios deste estudo. Foram selecionados 30 artigos para a leitura do resumo e discussão do assunto, além da utilização de livros considerados relevantes dentro do tema em questão.

\section{Discussão}

Diante do atual panorama econômico em que o País se encontra, em especial, o Estado do Rio de Janeiro, o Serviço de Segurança Pública vivencia um momento de grande desgaste, trazendo como consequência, fatores estressores que comprometem a qualidade vida do Policial Militar. Tais fatores podem ter suas origens dentro do próprio ambiente corporativo ou fora dele.

Como exemplo de alguns fatores Internos, destacamos: o assédio moral praticado dentro de uma rigidez hierárquica, escalas extras (não remuneradas) de serviço, más condições de trabalho (viaturas com defeitos, armamentos obsoletos, desfalque de coletes etc.), local de trabalho sem higiene adequada e os baixos salários.

Como exemplo de alguns fatores Externos, destacamos: o alto número de policiais mortos, a falta de reconhecimento, a sensação de injustiça ou de impunidade que as diversas ocorrências lhes possibilitam vivenciar, cobrança excessiva por parte da população e a sensação de abandono por parte do "Estado".

Tomando por base o assunto estudado e a relação com os relatos e depoimentos de diversos policiais militares que, frequentemente, são divulgados em pesquisas, como as de Souza e Minayo (2005) e Minayo, Souza e Constantino (2008), ou através das mídias, é possível identificar a insatisfação que permeia a prática da atividade profissional do policial militar. Não raramente, mencionam nunca terem tido um acompanhamento psicológico ou psiquiátrico, mesmo após ocorrências em que estiveram envolvidos. Se sentem pouco valorizados dentro da própria 
corporação ou fora dela. Suas jornadas de trabalho extrapolam a carga horária semanal que, normalmente, é desempenhada pela maioria dos trabalhadores, seja em suas funções como policiais militares ou no desempenho de outras atividades que buscam como "Bicos" a fim de que lhes sirvam para o complemento de renda devido à baixa remuneração, ou mesmo pelos dias de salários atrasados. Suas rotinas são, geralmente, acompanhadas de muita tensão. Não há como prever o que pode acontecer durante uma jornada de trabalho e a constante sensação de ameaça ou insegurança serve como elemento disparador de quadros como o estresse ou outros da ordem da psicossomática, podendo tornar o policial até incapaz para exercer suas atividades laborais.

De acordo com Minayo, Souza e Constantino (2008), o fato de superiores hierárquicos tratarem seus subordinados de forma agressiva e fora dos preceitos dos direitos constitucionais, causa descontentamento no trabalho e falta de produtividade do profissional. A pressão vivenciada pelo Policial Militar, em seu trabalho, consequentemente promove a queda de seu desempenho no serviço prestado à sociedade, gerando, entre outros fatores, a desmotivação para o trabalho, a desatenção e a exposição maior ao erro.

Autores como Lipp (1996) assinalam que a atividade militar não se resume apenas ao serviço diário, a função também implica em constante estado de alerta, mesmo quando o profissional encontra-se no seu momento de descanso. Sendo assim, a profissão do policial requer que o mesmo atue constantemente no confronto contra a conduta indevida ou criminosa da sociedade, defendendo cidadãos até mesmo em seus momentos da vida pessoal, fora de sua escala de trabalho.

Todas essas observações nos levam a identificar que combater o estresse e a ansiedade que acompanham o policial militar não é uma tarefa fácil. O sucesso deste trabalho demandará certo empenho da sociedade, bem como apoio dos familiares e o justo investimento do Estado. Esta é uma reflexão urgente diante das taxas absurdas de morte dos policiais e da população civil do Estado do Rio de Janeiro.

\section{Considerações finais}

Considerando o importante papel que uma atividade profissional exerce na vida e estrutura de um indivíduo e tendo em vista que os problemas resultantes do sofrimentopsíquiconas organizações sãoresponsáveis por boa parte dos adoecimentos e afastamentos do trabalho, espera-se, através deste estudo, contribuir, em termos práticos, para uma maior conscientização do Estado e da sociedade, em relação às situações vivenciadas, atualmente, pelo Policial Militar. Além disso, espera-se contribuir para que novas estratégias sejam propostas para uma efetiva mudança em relação à compreensão que se tem hoje sobre a Polícia Militar. Deve-se incluir em planejamentos, a curtíssimo prazo, uma ampla reestruturação a fim de que se resgate a confiança da sociedade na Instituição e a autoestima dos policiais militares, alterando completamente a cultura organizacional e o comportamento organizacional da Polícia Militar que temos hoje. Os Policiais Militares necessitam de treinamentos adequados, de condições adequadas para exercerem suas funções e de apoios psicológico e jurídico que lhes propiciem um acompanhamento antes, durante e após o desempenho de tarefas específicas que possam lhes causar uma desadaptação e, consequentemente, o estresse em alto grau e a infelicidade, desencadeando doenças psicossomáticas de diferentes ordens, fazendo com que esse profissional ultrapasse os limites saudáveis para a preservação de sua saúde física e mental.

\section{Referências Bibliográficas}

ALBRECHT, K. O gerente e o estresse: faça o estresse trabalhar para você. 2. ed. Rio de Janeiro: Zahar, 1990.

BALLONE, G. J. ; NETO, E.P. ; ORTOLANI, I. V. Da emoção à Lesão: Um guia de medicina psicossomática. 1 ${ }^{\text {a }}$. Ed. São Paulo: Editora Manole, 2002.

BRANT, L. C. ; MINAYO-GOMEZ, C. The transformation process of suffering into illness: from the birth of the clinic to the psychodynamic work. Ciência \& Saúde Coletiva, 9(1): 213-218, 2004

BRASIL. Ministério da Sáude/Organização Pan-Americana da Saúde \& Claves/Fiocruz. Impacto da Violência na Saúde dos Brasileiros (Orgs. SOUZA, E.R. \& MINAYO, M.C.S.). Brasília: Ministério da Saúde, 2005.

BRETAS, M. L. A polícia carioca no Império. Estudos Históricos, 12(22): 219-234, 1998

CODO, W; SAMPAIO, J. J. C.; HITOMI, A. H. Indivíduo, trabalho e sofrimento: uma abordagem interdisciplinar. 3. ed. Petrópolis: Vozes, 1993.

DELBONI, T.H. Vencendo o stress: como melhorar as condições de trabalho para viver melhor. São Paulo: Makron Books do Brasil, 1997.

FIGUEIRA, I. ; MENDLOWICZ, M. Diagnóstico do transtorno de estresse pós-traumático. Revista Brasileira de Psiquiatria, 25, supl. 1: 12-16, 2003.

GIDDENS, A. A transformação da intimidade: sexualidade, amor e erotismo nas sociedades modernas. 4 ed. São Paulo: UNESP, 2002.

HALL, S. A identidade cultural na pós-modernidade. Trad. Tomaz Tadeu da Silva. Guacira Lopes Louro. 7 ed. Rio de Janeiro: DP\&A, 2002.

HOLLOWAY, T. H. Polícia no Rio de Janeiro: repressão e resistência numa cidade do século XIX. Rio de Janeiro: Editora FGV, 1997.

ISP Disponível: http://www.ispdados.rj.gov.br/Arquivos/ SeriesHistoricasLetalidade Violenta. pdf Acessado em 28/10/2017

LIPP, M. E. N. O stress ocupacional e qualidade de vida. Anais do Simpósio sobre stress e suas implicações. Campinas: Pontifícia Universidade Católica de Campinas, (pp.42-45), 1996a.

LIPP, M. E. N. (Org.). Pesquisas sobre stress no Brasil: saúde, ocupações e grupos de risco. Campinas: Papirus, 1996b.

MINAYO, M.C.S.; SOUZA, E.R.; CONSTANTINO, P. (Coords). Missão prevenir e proteger: Condições de vida, trabalho e saúde dos policiais militares do Rio de Janeiro (online). Rio de Janeiro: Editora Fiocruz, 328p, 2008.

MINAYO M. C. S.; ASSIS S. G.; OLIVEIRA R. V. C. Impacto das atividades 
profissionais na saúde física e mental dos policiais civis e militares do Rio de Janeiro. Ciência \& Saúde Coletiva, 16(4): 2199-2209, RJ, Brasil, 2011.

MORAES, L. F. R.; KILIMNIK, Z. M. As dimensões básicas do trabalho, qualidade de vida e stress: uma análise em profissões de impacto na sociedade. Belo Horizonte: CEPEAD/UFMG. (Relatório de pesquisa), 1992.

PMERJ Disponível: https://pmerj.rj.gov.br/historia-da-pmerj/ acessado em 28/10/2017.

QUICK ET AL. O executivo em harmonia. São Paulo: Publifolha, 2003.

SILVA, M. B.; VIEIRA, S. B. O processo de trabalho do Militar Estadual e a Saúde Mental. Saúde e Sociedade, São Paulo, v. 17, n. 4, p. 161 a 170 , 2008. 